Human Ethology Bulletin 33 (2018) 1: 1-2

Letter from the Editorial Board

\title{
WHEN BACK IN THE DAY WAS IN THE HERE AND NOW
}

\section{Colin Hendrie}

Editor in Chief

In the early 1990s a conference was organised in Birmingham, UK by the late Steve Cooper and I to mark the 30th anniversary of the publication of two seminal papers to do with the ethological analysis of laboratory animal behaviour (Grant, 1963; Grant \& MacKintosh, 1963). This reunion of the Uffculme group, named after the laboratory where this work had been done under the supervision of Michael Chance, gave those at the conference a rare opportunity to meet with these pioneers face-to-face and to hear about the innovations they had made and the technological difficulties they had to overcome. The idea that laboratory animals were socially organised was deemed eccentric by non-ethologists back in the early 1960 s, and it is sad to report that this situation has not improved noticeably since that time, with most of those that work with laboratory animals remaining blind to the social complexities of the animals they work with (Hendrie et al, 2011). Paul Silverman gives a vivid account of this early work in his "Memoir of Uffculme" (Silverman, 1994) and explains how this laboratory came into being after Chance had become inspired by the then recently published "Study of Instinct" (Tinbergen, 1951).

One of the more intriguing aspects of this account was that, despite their having only soot-drum event recorders and electro-mechanical calculators to assist with calculations that all had to be done by hand, the methodology at the core of their ethological analysis was immediately recognisable and familiar.

Silverman explains "... the basic method ... was the same as that of Lorenz, Tinbergen and all the other ethologists: just watch. For long periods, again and again. At first, behaviour seems shapeless, elastic, and indeed for long periods nothing much seems to happen. Eventually regularities begin to emerge from the fog. You begin slowly to notice that you are 
seeing something that you have seen before. You begin to recognise a specific action or posture. You give it a name, and then you can begin to record ..." (Silverman, 1994, p 3).

This description reinforces two key points in ethology. Firstly, that the method is so powerful that it can be applied to any species in more-or-less any situation. It was no coincidence then that Chance, Grant and Mackintosh all eventually turned their focus onto human ethology (e.g. Chance, 1980; Grant 1969; MacKintosh et al, 1986; Kirk, 2009)). The second point is that whilst we as teachers can offer advice, information and insights into the ethological method per se (see Richer et al, 2017), the acquisition of the actual skills required to use an ethogram with reliability and confidence is essentially self-taught.

\section{REFERENCES}

Chance, M.R.A. (1980). An ethological assessment of emotion. In Theories of Emotion (pp. 81-111).. $\underline{\mathrm{DOI}}$

Grant, E.C. (1963). An analysis of the social behaviour of the male laboratory rat. Behaviour, 21(3), 260-281.

Grant, E.C. (1969). Human facial expression. Man, 4(4), 525-692. DOI

Grant, E.C., \& Mackintosh, J.H. (1963). A comparison of the social postures of some common laboratory rodents. Behaviour, 21(3), 246-259.

Hendrie, C.A. Phillips, D. \& Pickles A.R. (2011) Behavioural Scientists Appear Not to Have Specialist Knowledge of Laboratory Animal Behaviour Journal of Psychopharmacology 25, Suppl 8 A35.

Kirk, R.G. (2009). Between the clinic and the laboratory: ethology and pharmacology in the work of Michael Robin Alexander Chance, c. 1946-1964. Medical History, 53(4), 513-536. DOI

Mackintosh, J.H., Knight, R., \& Kumar, R. (1986). Ethological studies of depressed patients. Schweizer Archiv für Neurologie, Neurochirurgie und Psychiatrie.,137, 165-170.

Richer, J., Hendrie, C.A., Oberzaucher, E., Fisher, M.L., Segal, N. (2017). Direct Observation of Human Behaviour. What It Is and Why It Must Be Done. Human Ethology Bulletin, 32 (4), 3-5. DOI

Silverman A.P. (1994). A memoir of Uffculme In: Cooper, S.J., \& Hendrie, C.A. (Eds.). Ethology and psychopharmacology. Wiley.

Tinbergen, N. (1951). The study of instinct. Oxford University Press. 